\title{
Effect of Carboxylate Compounds on the Electrochemical Behavior of Dopamine at a Mercury Electrode
}

\author{
Eduardo Winter, Rosangela M. de Carvalho, Lauro T. Kubota and Susanne Rath* \\ Instituto de Química, Universidade Estadual de Campinas, CP 6154, 13084-971, Campinas - SP, Brazil
}

\begin{abstract}
A oxidação eletroquímica da dopamina leva à deposição de filmes poliméricos sobre a superfície de eletrodos sólidos, diminuindo a atividade dos mesmos. No eletrodo de mercúrio o processo redox ocorre na região de potencial de oxidação do mercúrio. No entanto, na presença de compostos carboxílicos o voltamograma cíclico da dopamina, no eletrodo de mercúrio, é diferenciado e apresenta um novo produto eletroativo proveniente do processo de oxidação da dopamina. O presente trabalho descreve resultados preliminares sobre o comportamento eletroquímico da dopamina no eletrodo de mercúrio na presença de acetato, citrato e EDTA.
\end{abstract}

The electrochemical oxidation of dopamine leads to deposition of polymeric films on the surfaces of solid state electrodes, decreasing the electrode activity. With a mercury electrode, the oxidation of dopamine occurs in the potential region of mercury oxidation. However, in the presence of carboxylic compounds the cyclic voltammogram of dopamine is different and presents a new electroactive product resulting from the oxidation of dopamine. This work describes preliminary results for the electrochemical behavior of dopamine at the $\mathrm{Hg}$-electrode in the presence of acetate, citrate and EDTA.

Keywords: dopamine, electrochemical behavior, carboxylate compounds, mercury electrode

\section{Introduction}

Over the last 50 years a considerable number of reports about the electrochemical behavior of catecholamines and other biogenic amines has been described in the literature. ${ }^{1-3}$ Interest in the redox behavior of catecholamines is related to the fact that some of these compounds are directly involved in neurotransmition processes. Several neurological disorders, in particular Parkinson's disease, are associated with improper catecholamine (dopamine) regulation. ${ }^{4}$ New research on the pathology and treatment of these diseases requires the development of new analytical methods for dopamine (3,4-dihydroxyphenylethylamine) determination.

Dopamine (DA) is an unstable phenolic compound, which undergoes oxidation in neutral or alkaline solutions in the presence of oxygen, with the formation of dopaminochrome and other polymeric compounds. ${ }^{5-7}$

Several methods have been reported for the determination of dopamine, including spectrophotometry, ${ }^{8}$

* e-mail: raths@iqm.unicamp.br spectrofluorimetry, ${ }^{9}$ radioimmunoassay ${ }^{10}$ and high performance liquid chromatography with electrochemical detection. ${ }^{11}$ In spite of the electrochemical activity of dopamine, electrochemical methods, due to their high sensitivity, are of special interest in the quantification of DA. ${ }^{12}$ However, the electrochemical determination of phenolic compounds presents some problems due to the loss of electrode activity of some solid state electrodes, like platinum, glassy carbon and pyrolytic graphite, during the oxidation process. This electrode inactivation may be explained by the accumulation of reaction products, forming electro-polymerized films on the surface of the electrode. In order to reduce the phenomenon of electrode poisoning, modified electrodes for catecholamine determination had been investigated. ${ }^{13-15}$

The mercury electrode was widely employed, in the past, in voltammetric methods for the determination of metals as well as organic substances. The surface phenomenon observed with some kinds of solid state electrodes is not of great relevance here, however, DA could not be determined by voltammetry employing a mercury electrode, owing to the fact that the oxidation of the compound occurs at a potential more positive than that for mercury oxidation..$^{15-17}$ 
In preliminary studies, it was verified that cyclic voltammograms, employing the mercury electrode, made in the presence of citrate produced a well defined peak in the anodic scan for DA, which appears at a lower potential than that for mercury oxidation. ${ }^{18}$ Based on this observation, an investigation of the electrochemical behavior of DA the mercury electrode in the presence of carboxylic compounds is presented.

\section{Experimental}

\section{Electrochemical studies}

All voltammetric measurements were carried out with a potentiostat-galvanostat - Autolab $^{\circledR}$ PGSAT-30 (Eco Chemie B. V.; The Netherlands). Platinum wire was used as a counter electrode and all potentials were recorded against a saturated calomel reference electrode (SCE). The hanging mercury drop electrode was employed as the working electrode.

In the voltammetric experiments the potential was scanned in the range from +250 up to $-400 \mathrm{mV}$, using 20 $\mathrm{mL}$ of solution containing the supporting electrolyte $(0.1$ mol L-1 $\mathrm{KNO}_{3}$ ), the carboxylic compound and DA. Pure $\mathrm{N}_{2}$ was bubbled through the sample solutions for $10 \mathrm{~min}$ before the voltammetric measurements.

For the studies employing a.c. polarography the following conditions were employed: $\Delta \mathrm{E}: 15 \mathrm{mV}, \varphi: 90^{\circ}$, frequency: $75 \mathrm{~Hz}$, drop time: $0.6 \mathrm{~s}$ and scan rate: $6 \mathrm{mV} \mathrm{s}^{-1}$.

\section{Chemicals and solutions}

Dopamine (3,4-dihydroxyphenylethylamine, DA) was an analytical grade reagent purchased from Sigma-Aldrich. Ethylenediaminetetraacetic acid dissodium salt dihydrate $\left(\mathrm{Na}_{2} \mathrm{H}_{2}\right.$ EDTA $) .2 \mathrm{H}_{2} 0$ was acquired from Nuclear, Brazil and sodium acetate, acetic acid, sodium citrate and potassium nitrate from Merck, Brazil. All reagents were used without any previous purification.

The working standard solutions were freshly prepared by dissolving DA in deionized water (Milli- $Q$ ).

For $\mathrm{pH}$ measurements, a Digimed DM-20 pHmeter was used.

\section{Results And Discussion}

\section{Cyclic Voltammetry of DA in the absence and presence of citrate}

The oxidation of DA at the mercury electrode, employing $\mathrm{KNO}_{3}$ as supporting electrolyte, occurs at a potential higher than that for mercury oxidation and, in consequence, no anodic peak in the cyclic voltammogram could be observed (Figure 1a). Nevertheless, a cathodic peak (I) at $+200 \mathrm{mV}$ was registered. Despite the large current, this peak is superimposed by the mercury redox process (Figure 2) and, in consequence, is not suitable for quantitative purposes. The symmetric form of peak (I) suggests the presence of adsorption phenomena. In the presence of citrate, the cathodic peak potential $\left(\mathrm{E}_{\mathrm{pc}} \mathrm{I}\right)$ is shifted to more negative potentials and the current intensity diminishes significantly.

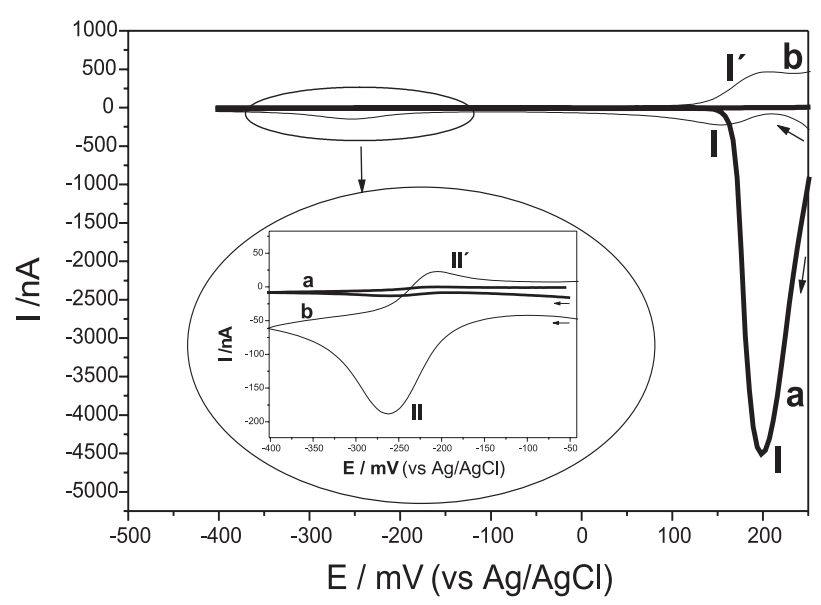

Figure 1. Cyclic voltammograms obtained for $1 \times 10^{-3} \mathrm{~mol} \mathrm{~L}^{-1} \mathrm{DA}$ in (a) $0.1 \mathrm{~mol} \mathrm{~L}^{-1} \mathrm{KNO}_{3}$, pH 7.0; (b) $0.1 \mathrm{~mol} \mathrm{~L}^{-1} \mathrm{KNO}_{3}+0.1 \mathrm{~mol} \mathrm{~L}^{-1}$ citrate, $\mathrm{pH}$ 7.0. Scan rate: $20 \mathrm{mV} \mathrm{s}^{-1}$.

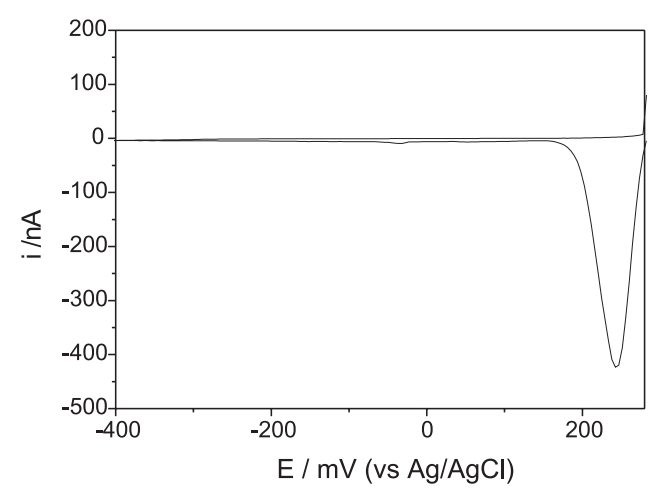

Figure 2. Cyclic voltammograms obtained for $0.1 \mathrm{~mol} \mathrm{~L}^{-1} \mathrm{KNO}_{3}$, $\mathrm{pH}$ 7.0. $\mathrm{E}_{\mathrm{i}}:+250 \mathrm{mV}$; $\mathrm{E}_{\lambda}:-400 \mathrm{mV}$. Scan rate: $20 \mathrm{mV} \mathrm{s}^{-1}$.

Upon addition of citrate to the supporting electrolyte, the formation of a redox couple (II) and (II'), at $-260 \mathrm{mV}$ and $-210 \mathrm{mV}$, respectively, occurs (Figure $1 \mathrm{~b}$ ). These peaks depend on the initial applied potential for the cathodic scan. When the scan is carried out from $-400 \mathrm{mV}$ to +250 $\mathrm{mV}$, the anodic peak (II) only appears in the second scan. Similar behavior was observed when the cyclic voltammogram was scanned from -50 to $-400 \mathrm{mV}$, in which peaks (II) and (II') could not be observed (Figure 3a), e.g. 
the redox couple (II/II') only appears if the initial applied potential is high enough to allow the oxidation of DA at the electrode surface before the cathodic scan (Figure 3b). The prior oxidation of DA in the presence of citrate leads to the formation of a new electroactive species.

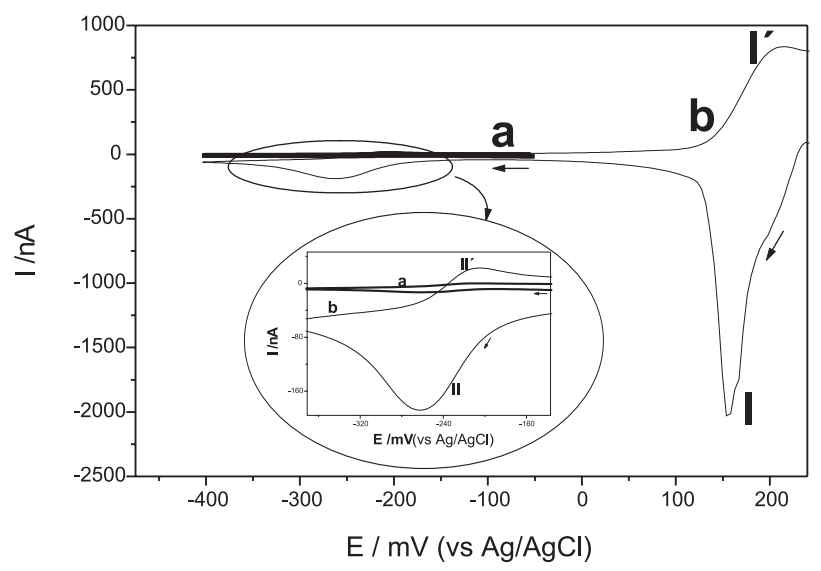

Figure 3. Cyclic voltammograms obtained for $1.0 \times 10^{-3} \mathrm{~mol} \mathrm{~L}^{-1} \mathrm{DA}$ $+0.1 \mathrm{~mol} \mathrm{~L}^{-1}$ citrate in $0.1 \mathrm{~mol} \mathrm{~L}^{-1} \mathrm{KNO}_{3} \mathrm{pH}$ 7.0. a) $\mathrm{E}_{\mathrm{i}}:-50 \mathrm{mV}$; $\mathrm{E}_{\lambda}$ : - $400 \mathrm{mV}$. b) $\mathrm{E}_{\mathrm{i}}:+250 \mathrm{mV} ; \mathrm{E}_{\lambda}:-400 \mathrm{mV}$. Scan rate: $20 \mathrm{mV} \mathrm{s}^{-1}$.

These results suggest that the cathodic peak current $i_{p c}$ (II) results from the reduction of a product formed by the reaction between citrate and some product formed during DA oxidation that anodic peak current $i_{\mathrm{pa}}$ (II') is due to the oxidation of the resulting compound by electrochemical process II.

In $0.1 \mathrm{~mol} \mathrm{~L}^{-1} \mathrm{KNO}_{3}$, $\mathrm{pH} 7.0$, a linear dependence between $\mathrm{i}_{\mathrm{pc}}$ (II) and DA concentration, in the range of 1.0x $10^{-4}$ to $1.4 \times 10^{-3} \mathrm{~mol} \mathrm{~L}^{-1}$, was observed, with the following equation: $\mathrm{i}_{\mathrm{pc}}=-7.6010^{4} \mathrm{C}-5.62$, where $\mathrm{i}_{\mathrm{pc}}$ : cathodic peak current II and C: concentration of DA in mol L-1 (Figure 4). This behavior could be exploited for quantitative purposes.

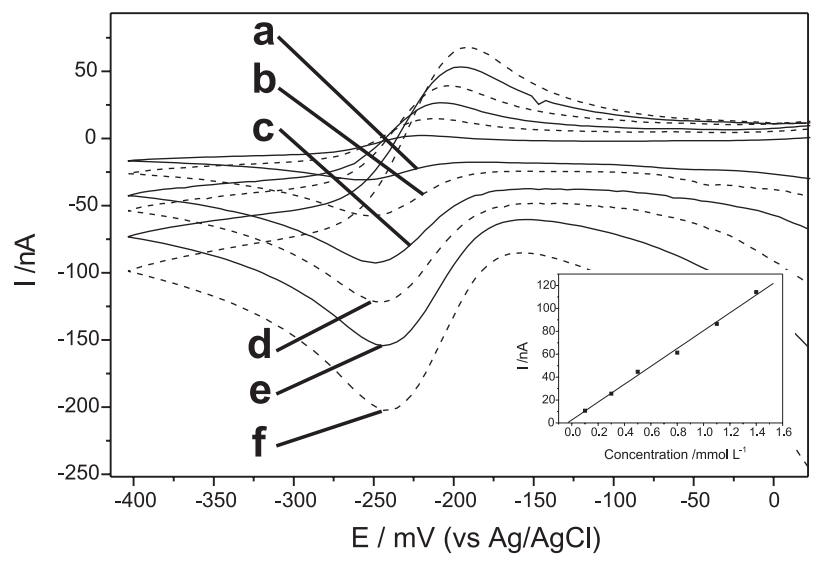

Figure 4. Cyclic voltammograms obtained for successive additions of dopamine in $0.1 \mathrm{~mol} \mathrm{~L}^{-1} \mathrm{KNO}_{3}, \mathrm{pH} 7.0$ in the presence of $0.01 \mathrm{~mol} \mathrm{~L}^{-1}$ citrate. a) $1.0 \times 10^{-4} \mathrm{~mol} \mathrm{~L}^{-1} \mathrm{DA}$; b) $3.0 \times 10^{-4} \mathrm{~mol} \mathrm{~L}^{-1} \mathrm{DA}$; c) $5.0 \times 10^{-4} \mathrm{~mol} \mathrm{~L}-1 \mathrm{DA}$; d) $8.0 \times 10^{-4} \mathrm{~mol} \mathrm{~L}^{-1} \mathrm{DA}$; e) $1.0 \times 10^{-3} \mathrm{~mol} \mathrm{~L}^{-1} \mathrm{DA}$; f) $1.4 \times 10^{-3} \mathrm{~mol} \mathrm{~L}{ }^{-1} \mathrm{DA} ; \mathrm{E}_{i}:+250 \mathrm{mV} ; \mathrm{E}_{\lambda}:-400 \mathrm{mV}$. Scan rate: $20 \mathrm{mV} \mathrm{s}$.

\section{Effect of the $p H$}

The $\mathrm{i}_{\mathrm{pc}}$ (II) depends on the proton concentration of the supporting electrolyte composed of $\mathrm{KNO}_{3}$ and citric acid (Figure 5), where three regions can be defined: (a) $2.0<\mathrm{pH}$ $<3.5$, where no peak was registered; (b) $3.5<\mathrm{pH}<6.4$, $\mathrm{i}_{\mathrm{pc}}$ (II) is independent of the solution $\mathrm{pH}$ and (c) $\mathrm{pH}>6.4$ where the $i_{p c}$ (II) depends strongly on the proton concentration of the medium $(-58.3 \mathrm{nA} / \mathrm{pH})$.

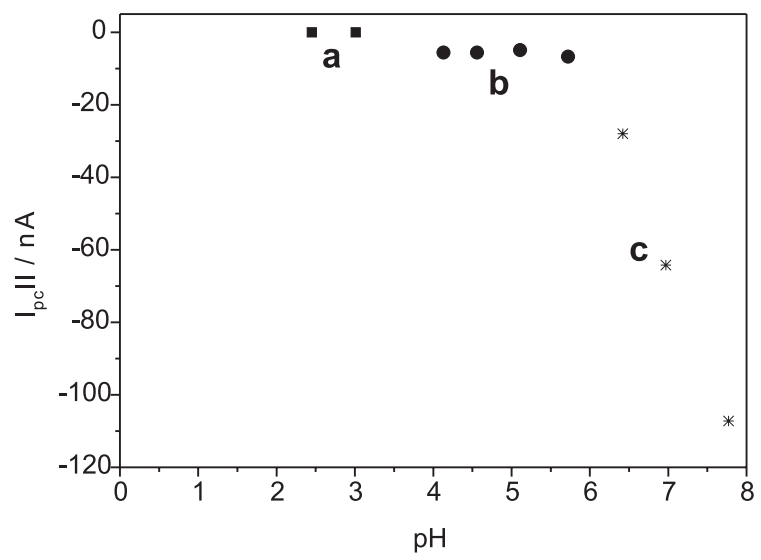

Figure 5. Behavior of $\mathrm{i}_{\mathrm{c}}$ (II) as a function of the $\mathrm{pH}$ value of the supporting electrolyte $\left(0.1 \mathrm{~mol} \mathrm{~L}^{-1} \mathrm{KNO}_{3}\right)$. Concentration of DA: $1 \times 10^{-3} \mathrm{~mol} \mathrm{~L}^{-1}$. Scan rate: $20 \mathrm{mV} \mathrm{s}^{-1} ; \mathrm{E}_{1}: 300 \mathrm{mV}, \mathrm{E}_{\lambda}$ : $-400 \mathrm{mV}$.

The changes in the behavior of $i_{p c}$ (II) as a function of the solution $\mathrm{pH}$ of the supporting electrolyte are correlated to the $\mathrm{pKa}$ values of the citric acid $\left(\mathrm{pKa}_{1}: 3.13 ; \mathrm{pKa}_{2}: 4.76\right.$ and $\left.\mathrm{pKa}_{3}: 6.40\right)$. These results indicate that the product formed with citrate after oxidation of DA depends on the acid-base equilibrium of the citric acid, where the formation of the electroactive species responsible for the formation of the electroactive specie II is favored when the carboxylate ions of the citrate are deprotonated. At $\mathrm{pH}<3.5$, where the three carboxylic groups of the citrate are protonated, the formation of the electroactive compound did not take place.

The peak potential $\mathrm{E}_{\mathrm{pc}}$ (II) also depends on the proton concentration between pH 5.0 to 7.8 (Figure 6), where it is shifted towards negative values with increasing $\mathrm{pH}$ values $(80.8 \mathrm{mV} / \mathrm{pH})$. These results indicate that: (i) the protonation of the electroactive specie II is rate determining compared to the electron transfer reaction process and/or (ii) different compounds between citrate and the product from dopamine oxidation are formed. The last hypothesis is reinforced by the, fact that in this $\mathrm{pH}$ region, citrate presents two different forms $\left(\mathrm{HCit}^{2-} / \mathrm{Cit}^{3-}\right)$.

\section{Influence of the carboxylic compound}

The interesting electrochemical behavior of DA in the 


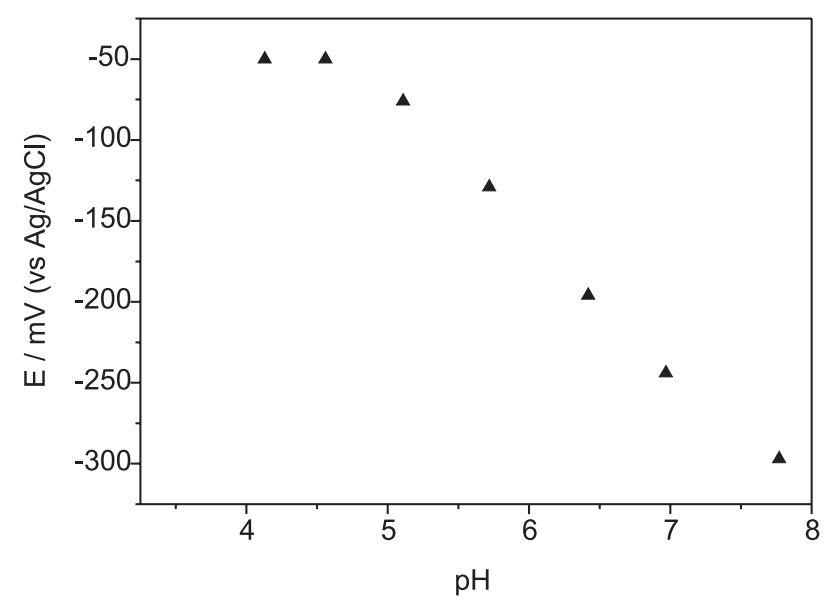

Figure 6. Behavior of $\mathrm{E}_{\mathrm{pc}}$ (II) as a function of the $\mathrm{pH}$-value of the supporting electrolyte $\left(0.1 \mathrm{~mol} \mathrm{~L}^{-1} \mathrm{KNO}_{3}\right)$. Scan rate: $20 \mathrm{mV} \mathrm{s}{ }^{-1} ; \mathrm{E}_{\lambda}$ : $300 \mathrm{mV}, \mathrm{E}_{1}:-400 \mathrm{mV}$.

presence of citrate leads to the following hypothesis: a product formed by the oxidation of DA forms a stable compound with the carboxylic compound in the electrical double layer. This compound is subsequently reduced. In this case the structure of the molecule and the number of carboxylic groups should be important for reduction. In order to verify these assumptions, two studies were carried out: (i) employing carboxylic compounds containing one to three carboxylic groups in the same molecule, however maintaining their molar concentrations constant, and (ii) employing two carboxylic compounds, with one or three carboxylic groups, however maintaining constant the total number of carboxylic groups in solution. In all studies the respective carboxylic compounds were added to $0.1 \mathrm{~mol} \mathrm{~L}^{-1}$ $\mathrm{KNO}_{3}, \mathrm{pH} 7$.

In Figure 7, it can be verified that $i_{p c}$ (II) depends on the identity of the carboxylic compound employed and increases in the following order: acetate $<$ citrate $<$ EDTA. The peak potential $\left(\mathrm{E}_{\mathrm{pc}} \mathrm{II}\right)$ is shifted to more negative values in the same order, suggesting that carboxylic compounds with three deprotonated carboxylic groups form more stable products with the oxidized dopamine than compounds with only one carboxylic group.

In the second study, acetate and citrate were added to the supporting electrolyte. For acetate, with one carboxylic group, the three carboxylic acids concentration was set at three times the concentration for citrate, which presents in its structure. As shown in Figure 8, even the concentration of acetate being three times higher than the citrate concentration, the current did not increase at the same magnitude. These results reinforce the first hypothesis and indicate that the product formed by electrochemical oxidation of DA, which is reduced at $-260 \mathrm{mV}$, interacts with the carboxylic compound, forming a more stable compound.

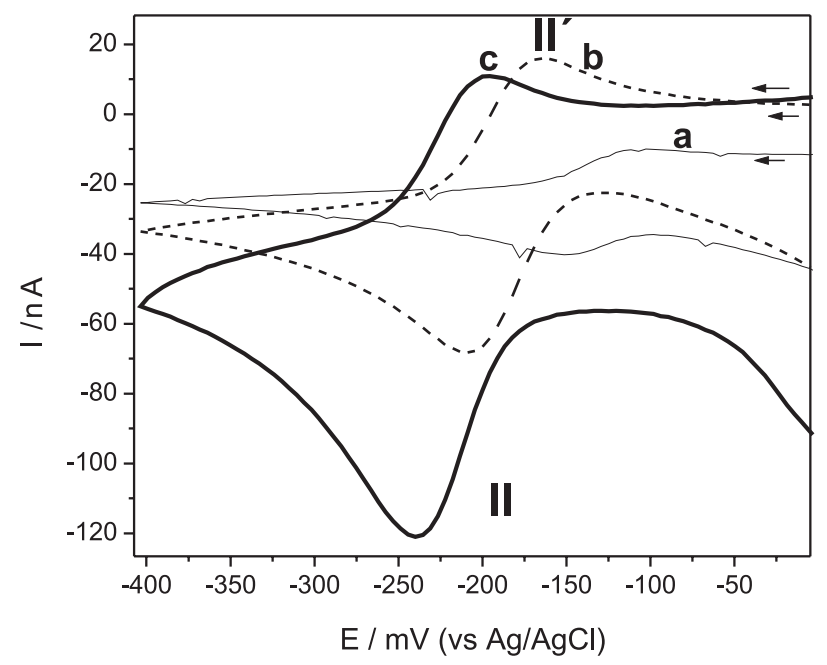

Figure 7. Cyclic voltammograms obtained for $1.0 \times 10^{-3} \mathrm{~mol} \mathrm{~L}^{-1} \mathrm{DA}$ in $0.1 \mathrm{~mol} \mathrm{~L}^{-1} \mathrm{KNO}_{3} \mathrm{pH} 7.0$, in presence of: a) $1.010^{-2} \mathrm{~mol} \mathrm{~L}^{-1}$ acetate b) $1.0 \times 10^{-2} \mathrm{~mol} \mathrm{~L}^{-1}$ citrate c) $1.0 \times 10^{-2} \mathrm{~mol} \mathrm{~L}^{-1}$ EDTA. Scan rate: $20 \mathrm{mV} \mathrm{s}^{-1} ; \mathrm{E}_{1}: 300 \mathrm{mV}, \mathrm{E}_{\lambda}:-400 \mathrm{mV}$.

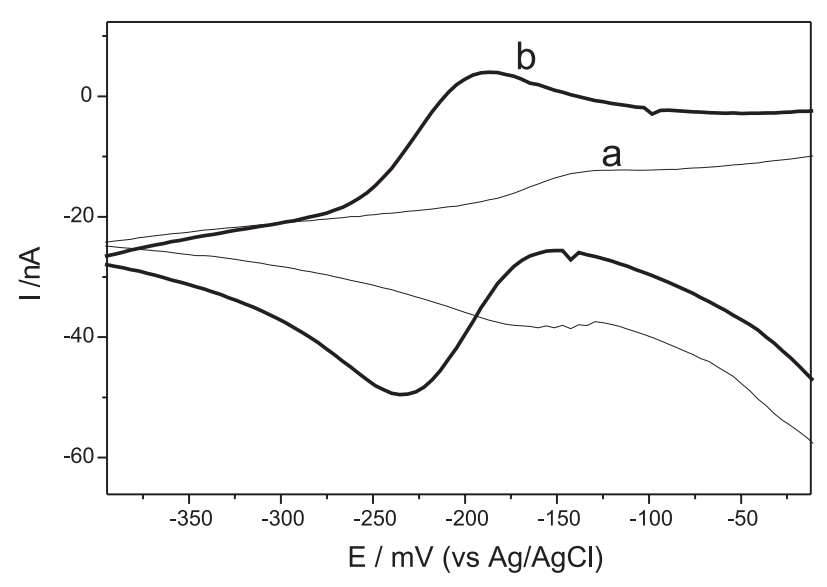

Figure 8. Cyclic voltammograms obtained for $1.0 \times 10^{-3} \mathrm{~mol} \mathrm{~L}^{-1} \mathrm{DA}$ in $0.1 \mathrm{~mol} \mathrm{~L}^{-1} \mathrm{KNO}_{3}, \mathrm{pH} 7.0$, in presence of: a) $4.0 \times 10^{-3} \mathrm{~mol} \mathrm{~L}^{-1}$ acetate b) $1.3 \times 10^{-3} \mathrm{~mol} \mathrm{~L}^{-1}$ citrate. Scan rate: $20 \mathrm{mV} \mathrm{s}^{-1} ; \mathrm{E}_{\mathrm{l}}: 300 \mathrm{mV}$, $\mathrm{E}_{\lambda}:-400 \mathrm{mV}$.

\section{ac polarography}

ac polarography was employed to verify possible adsorption phenomena during the electrochemical process for DA. The phase angle was adjusted to $90^{\circ}$ in order to measure only the capacitive current. Figure 9 shows that the addition of citrate to $\mathrm{KNO}_{3}$ leads to a decrease in the capacitance, with a maximum at $220 \mathrm{mV}$, indicating that the mercury-citrate complex adsorbs on the electrode surface. At potentials more negative than $-100 \mathrm{mV}$ the molecules desorb from the surface and the current converges towards the current from the supporting electrolyte $\left(\mathrm{KNO}_{3}\right)$. In the presence of DA and citrate, the ac polarogram (Figure 9c) indicates that the oxidized DA 
also adsorbs on the electrode surface at positive potentials At approximately $-200 \mathrm{mV}$, the capacitive current overcomes the current from the supporting electrolyte and at more negative potentials it converges to the current obtained only for the supporting electrolyte, indicating that after the charge transfer process (peak II), the products are not adsorbed on the electrode surface.

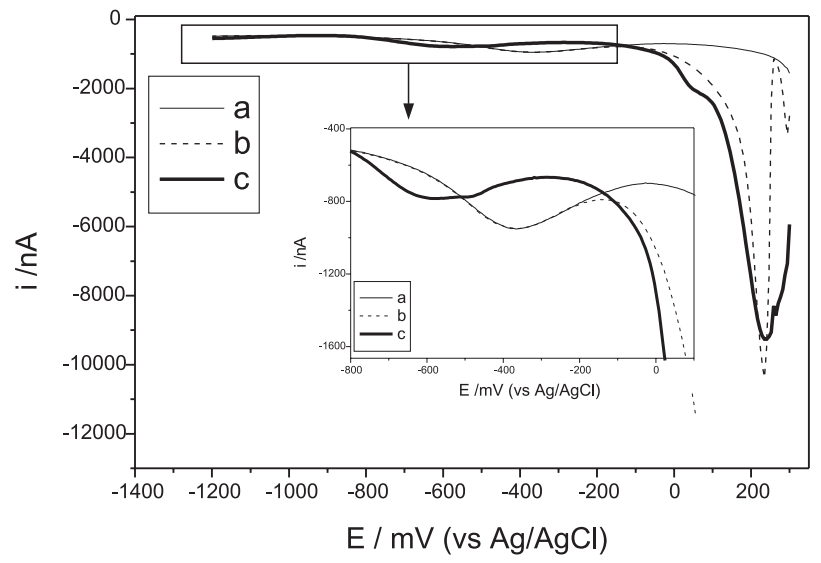

Figure 9. ac polarogramms. a) $0.1 \mathrm{~mol} \mathrm{~L}^{-1} \mathrm{KNO}_{3}$; b) $0.1 \mathrm{~mol} \mathrm{~L}^{-1}$ $\mathrm{KNO}_{3}+5 \times 10^{-3} \mathrm{~mol} \mathrm{~L}{ }^{-1}$ citrate; c) $0.1 \mathrm{~mol} \mathrm{~L}^{-1} \mathrm{KNO}_{3}+5 \times 10^{-3} \mathrm{~mol} \mathrm{~L}^{-1}$ citrate $+1 \times 10^{-3} \mathrm{~mol} \mathrm{~L}^{-1} \mathrm{DA}$.

\section{Influence of scan rate}

The cyclic voltammograms obtained for DA in the presence of citrate show that the $i_{p c}$ (II) is a linear function of the square root of the scan rate between 10 to $100 \mathrm{mV} \mathrm{s}^{-1}$, e.g. the process is diffusion controlled. With a scan rate of $5 \mathrm{mV} \mathrm{s}^{-1}$ the current was lower than that expected for a diffusion controlled process (Figure 10). Furthermore, the peak potential is shifted towards a more negative potential in relation to the higher scan rates, where the peak potential is independent of the scan rate (Figure 11).

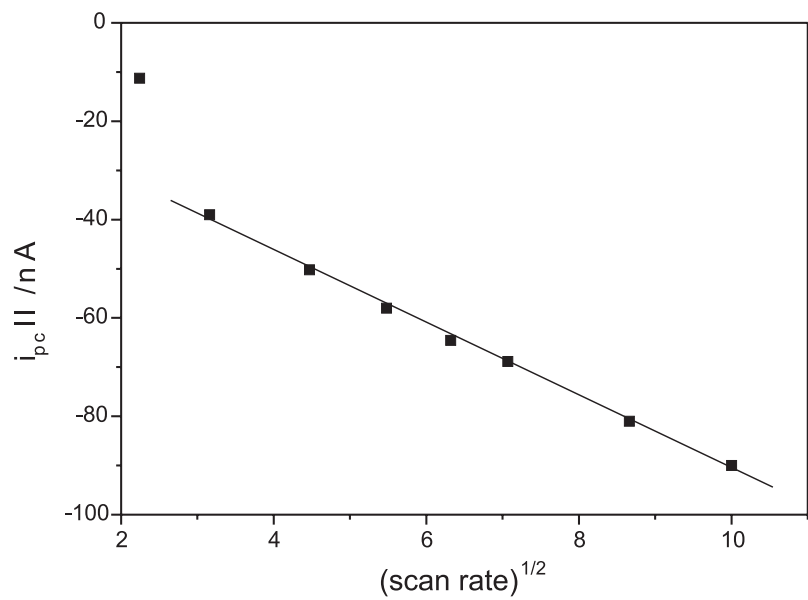

Figure 10. Variation of the $i_{p c}$ (II) as a function of the square root of the scan rate. $1.0 \times 10^{-3} \mathrm{~mol} \mathrm{~L}^{-1} \mathrm{DA}+1.0 \times 10^{-2} \mathrm{~mol} \mathrm{~L}^{-1}$ citrate in $0.1 \mathrm{~mol} \mathrm{~L}^{-1}$ $\mathrm{KNO}_{3}$, pH 7.0. Scan rate: $20 \mathrm{mV} \mathrm{s}{ }^{-1} ; \mathrm{E}_{1}: 300 \mathrm{mV}, \mathrm{E}_{\lambda}:-400 \mathrm{mV}$.
The abnormally low current intensity verified for the scan rate of $5 \mathrm{mV} \mathrm{s}^{-1}$ accompanied by the potential shift suggests that other products are formed in the double layer by chemical reactions of species (II) and that determination of the presence of $i_{p c}$ (II) is also kinetically controlled.

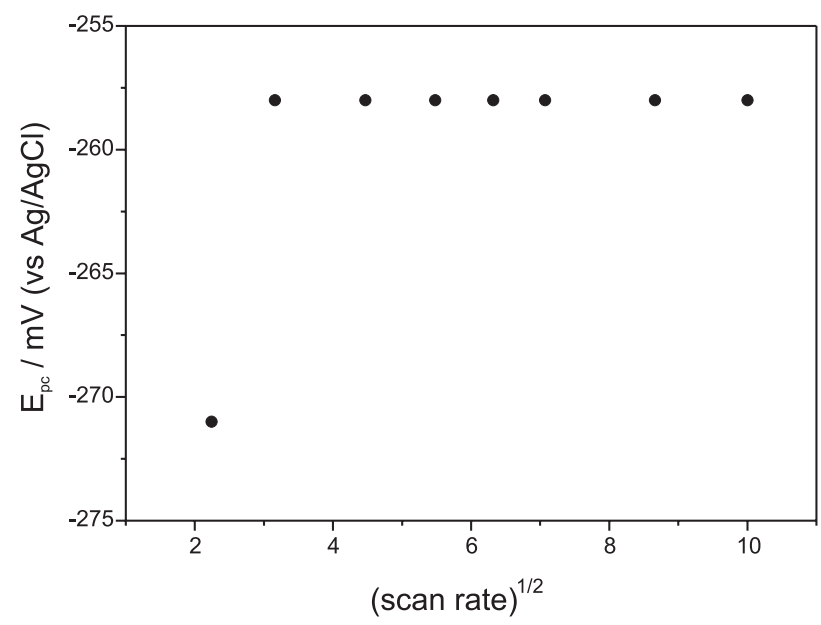

Figure 11. Variation of the $\mathrm{E}_{\mathrm{pc}}$ (II) as a function of the square root of the scan rate. $1.0 \times 10^{-3} \mathrm{~mol} \mathrm{~L}^{-1} \mathrm{DA}+1.0 \times 10^{-2} \mathrm{~mol} \mathrm{~L}^{-1}$ citrate in $0.1 \mathrm{~mol} \mathrm{~L}^{-1}$ $\mathrm{KNO}_{3}, \mathrm{pH}$ 7.0. Scan rate: $20 \mathrm{mV} \mathrm{s}^{-1} ; \mathrm{E}_{1}: 300 \mathrm{mV}, \mathrm{E}_{\lambda}:-400 \mathrm{mV}$.

\section{Conclusions}

The electrochemical behavior of DA at the mercury electrode in the presence of citrate is different, in comparison with that in the absence of this species. The mechanism involved to explain the electrochemical behavior of DA in the presence of carboxylic compounds is a subject for a further investigation. However, these preliminary results suggest the following reaction pathways:

$$
\begin{aligned}
& \left.\left.\begin{array}{rl}
\mathrm{DA}-2 \mathrm{e}^{-} /-2 \mathrm{H}^{+} & \rightleftarrows \mathrm{DA}_{\text {oxi }} \\
\mathrm{Hg}^{0}+\mathrm{R}(\mathrm{COO}) \mathrm{n}-2 \mathrm{e}^{-} & \rightleftarrows\left[\mathrm{Hg}(\mathrm{R}(\mathrm{COO}) \mathrm{n}]^{-\mathrm{n}+2}\right.
\end{array}\right\} \text { [species } \mathrm{I} / \mathrm{I}^{\prime}\right] \\
& \mathrm{DA}_{\text {oxi }}+\mathrm{R}\left(\mathrm{COO}^{\circ}\right) \mathrm{n} \quad \rightleftarrows \quad \mathrm{DA}_{\text {oxi }} \mathrm{R}\left(\mathrm{COO}^{\circ}\right) \mathrm{n} \\
& \mathrm{DA}_{\text {oxi }} \mathrm{R}\left(\mathrm{COO}^{-}\right) \mathrm{n}+\mathrm{xe}^{-} / \mathrm{mH}^{+} \rightleftarrows \quad \mathrm{DA}_{\text {red }} \mathrm{R}\left(\mathrm{COO}^{-}\right) \mathrm{n} \quad \text { [species II/II'] } \\
& \mathrm{DA}_{\text {oxi }} \mathrm{R}(\mathrm{COO}) \mathrm{n} \longrightarrow \text { Electroinactive Product(s) }
\end{aligned}
$$

In the first step, applying $300 \mathrm{mV}$, DA undergoes oxidation at the mercury electrode with the formation of $\mathrm{DA}_{\text {oxi }}$. At the same time mercury, in the presence of citrate, is oxidized. These reactions justify the complex behavior observed at positive potentials in the cyclic voltammograms (peak I). Both electrochemical reactions proceed with the molecules in the adsorbed state. The product formed by the DA oxidation undergoes a chemical reaction with the carboxylic compound (citrate) forming a new electroactive species $\mathrm{DA}_{\text {oxi }} \mathrm{R}\left(\mathrm{COO}^{-}\right) \mathrm{n}$, which could be 
reduced to $\mathrm{DA}_{\text {red }} \mathrm{R}\left(\mathrm{COO}^{-}\right) \mathrm{n}$ at $-260 \mathrm{mV}$ (peak II). This product, on this time scale, remains at the electrode surface and undergoes oxidation in the successive anodic scan (peak II'). The chemical reaction proceeds and other electroinactive compounds from species (II) are formed. Whereas at low scan rates $\left(5 \mathrm{mv} \mathrm{s}^{-1}\right)$ the concentration of species (II) diminishes in the double layer and the current is kinetically controlled, at higher scan rates the process is diffusion controlled.

These preliminary results suggest an ECE (Electrochemical Chemical Electrochemical) mechanism for the DA at the mercury electrode.

The complete mechanism required to explain the electrochemical behavior of DA in the presence of carboxylic acids is the subject of a continuing investigation. However, these preliminary results show the potential for quantification of DA at a mercury electrode, with the advantage that no electrode passivation occurs.

Furthermore, carboxylic compounds are found in the cerebral fluid and the understanding of the interaction of DA with these carboxylates might be relevant from the biochemical viewpoint.

\section{Acknowledgements}

The authors thank FAPESP for financial support (Proc. 01/07386-4).

\section{References}

1. Dryhurst G.; Kadish K. M.; Scheller F.; Renneberg R.; Biological Electrochemistry, Academic Press: New York, 1982, vol. 1.

2. Hawley M. D.; Tatawawa S. V.; Piekarsk S., Adams R. N.; J. Am. Chem. Soc. 1967, 89, 447.
3. Sulzer D.; Pothos E. N.; Rev. Neurosci. 2000, 11, 159.

4. Grossman, M.; Glosser, G.; Kalmanson, J.; Morris, J.; Stern, M.B.; Hurtig, H.I.; J. Neurol. Sci. 2001, 184, 123.

5. Rein, F. N.; Rocha, R. C.; Toma, H. E.; J. Inorg. Biochem. 2001, 85, 155.

6. Ashby, F. G.; Isen, A.M.; Turken, U.; Psychol. Rev. 1999, 106, 529.

7. Carlsson, A.; Hansson, L. O.; Waters, N.; Carlsson, M.L.; Life Sci. 1997, 61, 75.

8. Manini, P.; d'Ischia, M.; Lanzetta, R.; Parrilli, M.; Prota, G.; Bioorgan. Med. Chem. 1999, 7, 2525.

9. Wood, A. T.; Hall, M. K.; J. Chromatog. B 2000, 744, 221.

10. Riceebery, L. J.; Vunakis, H. V.; Levin, L.; Anal. Biochem. 1974, 60, 551.

11. Napolitano, A.; Pezzella, A.; Prota, G.; Tethahedron Lett. 1999, 40, 2833.

12. Venton, B. J.; Troyer, K. P.; Wightman, M.; Anal. Chem. 2002, $74,539$.

13. Liu, Y. C.; McCreery, R. L.; J. Am. Chem. Soc. 1995, 117, 11254.

14. DuVall, S. H.; McCreery, R. L.; Anal. Chem. 1999, 71, 4594.

15. DuVall, S. H.; McCreery, R. L.; J. Am. Chem. Soc. 2000, 122, 6759.

16. Koile, K. C.; Johnson, D. C.; Anal. Chem. 1979, 51, 741.

17. Yi, H.; Wu, K.; Hu, S.; Cui, D.; Talanta 2001, 55, 1205.

18. Winter, E.; Carvalho, R. M.; Kubota, L. T.; Rath, S.; Abstracts of the XIII Simpósio Brasileiro de Eletroquímica $e$ Eletroanalítica, Araraquara, SP, Brazil, 2002.

Received: February 3, 2003

Published on the web: August 12, 2003

FAPESP helped in meeting the publication costs of this article. 